\title{
ANALISIS FAKTOR DETERMINAN YANG MEMPENGARUHI KINERJA ORGANISASI RUMAH SAKIT (RS) SWASTA
}

\author{
Gen Norman Thomas \\ Accounting and Finance Department, Faculty of Economic and Communication, BINUS University \\ Jln. K.H. Syahdan No. 9, Palmerah, Jakarta Barat 11480 \\ gen_nt@binus.ac.id
}

\begin{abstract}
This study aims to reveal and clarify the influence of organizational culture, organizational commitment and public accountability to the organizational performance of Private Hospital in West Jakarta. This research is a quantitative study by the research method takes a sample of the population private hospitals in West Jakarta with respondent Hospital Director, Finance Manager, Marketing Manager, Research and Development Manager or HRD Manager for 40 people. Data was collected using a questionnaire to obtain data primier then it is processed using SPSS. The quality of the data was tested by using the validity test shows the data is valid, the reliability test obtain realible and classic assumptions test have normal curves, no multicollinearity and does not occur heterocedastity. The results of this study show the first hypothesis that the organizational culture (X1) showed no significant effect on the performance of private hospitals (Y). The second hypothesis indicates that organizational commitment (X2) does not affect the performance of private hospitals $(Y)$. The third hypothesis testing shows that public accountability (X3) has a significant influence on the performance of private hospitals $(Y)$. The fourth hypothesis that organizational culture (X1), organizational commitment (X2), and public accountability (X3) simultaneously have a significant influence on the organizational performance of private hospitals $(Y)$.
\end{abstract}

Keywords: organizational culture, organizational commitment, public accountability, organizational performance

\begin{abstract}
ABSTRAK
Penelitian ini bertujuan untuk mengungkapkan dan memperjelas pengaruh faktor Budaya Organisasi, Komitmen Organisasi dan Akuntabilitas Publik terhadap Kinerja Organisasi RS Swasta di Jakarta Barat. Penelitian ini adalah penelitian kuantitatif dan asosiatif dengan metode penelitian yang mengambil sampel dari populasi Rumah Sakit Swasta di Jakarta Barat dengan responden Direktur Rumah Sakit, Manajer Keuangan, Manajer Marketing, Manajer Penelitian dan Pengembangan dan Manajer SDM sejumlah 40 orang. Teknik pengumpulan data dilakukan dengan menggunakan kuestioner untuk memperoleh data primier kemudian diolah dengan menggunakan SPSS. Kualitas data diuji dengan menggunakan uji validitas menunjukan data valid, uji reabilitas menunjukan data reliable dan uji asumsi klasik menunjukan data berkurva normal, tidak ada multikolinearitas dan tidak terjadi heterokedastisitas. Hasil penelitian ini menunjukkan pada hipotesis pertama bahwa budaya organisasi (X1) tidak menunjukkan pengaruh yang signifikan terhadap kinerja RS swasta (Y). Hipotesis kedua menunjukkan bahwa komitmen organisasi (X2) juga tidak berpengaruh signifikan terhadap kinerja RS swasta (Y). sedangkan pengujian hipotesis ketiga menunjukkan bahwa akuntabilitas publik (X3) mempunyai pengaruh yang signifikan terhadap kinerja RS swasta (Y). Hipotesis keempat bahwa budaya organisasi (X1), komitmen organisasi (X2), dan akuntabilitas publik (X3) secara bersama-sama mempunyai pengaruh yang signifikan terhadap kinerja organisasi RS Swasta di Jakarta Barat (Y).
\end{abstract}

Kata kunci: budaya organisasi, komitmen organisasi, akuntabilitas publik, kinerja organisasi 


\section{PENDAHULUAN}

Rumah Sakit (RS) adalah organisasi yang kompleks yang bekerja dengan menggunakan gabungan alat ilmiah khusus dan rumit yang difungsikan oleh berbagai kesatuan personil yang terlatih dan terdidik dalam menangani masalah medis modern, yang semuanya terikat pada tujuan yang sama untuk pemulihan dan pemeliharaan kesehatan yang baik. WHO (World Health Organization) menyatakan bahwa rumah sakit adalah bagian integral dari suatu organisasi sosial dan kesehatan dengan fungsi menyediakan pelayanan komprehensif, penyembuhan penyakit (kuratif) dan pencegahan penyakit (preventif) kepada masyarakat, dan rumah sakit juga berfungsi sebagai tempat memberikan pelayanan medis dan pusat pelatihan bagi tenaga kesehatan dan pusat penelitian medis. Mengacu pada pentingnya fungsi pelayanan rumah sakit yang demikian vital bagi pemenuhan kesehatan masyarakat, maka kualitas pelayanan harus selalu terjaga secara terus menerus dan berkesinambungan. Pemerintah juga mendukung dengan mengesahkan undang-undang No. 44 Tahun 2009 yang menyatakan bahwa rumah sakit adalah institusi pelayanan kesehatan yang menyelenggarakan pelayanan kesehatan perorangan secara paripurna yang menyediakan pelayanan rawat inap, rawat jalan, dan gawat darurat.

Kenyataannya, kinerja organisasi RS tidak sepenuhnya memuaskan sebagaimana yang diharapkan karena masih ada pasien dan keluarga pasien yang tidak puas dengan pelayanan RS sebagai satu-satunya entitas penyelenggara kesehatan yang formal bagi masyarakat. Kasus Prita tahun 2009 yang berselisih dengan salah satu rumah sakit swasta di Tangerang adalah salah satu contoh. Prita merasa tidak puas dengan pelayanan medis rumah sakit dan yang bersangkutan menyampaikan ketidak puasannya ke rumah sakit tetapi tidak mendapatkan respon yang seharusnya. Atas inisiatif sendiri, Prita menyampaikan permasalahannya ke salah satu media sosial yang mempunyai dampak yang luas dan semua orang yang tadinya tidak mengetahui menjadi mengetahui permasalahannya. Mantan ketua IDI Azrul Azwra sempat mengatakan bahwa jika ada pasien mengeluh atas pelayanan RS, harusnya pihak rumah sakit mendengarkan dan memperbaiki bukan malah memenjarakan pasiennya. (Kompas.com, 2009). Hal ini belum termasuk kasus diskriminasi dalam pelayanan kesehatan antara pasien yang mampu dengan pasien yang kurang mampu. Masih banyak kasus-kasus lain yang berkaitan dengan buruknya pelayanan kesehatan, antara lain kasus pasien miskin yang terlantar di RSCM Jakarta, kasus kurang gizi sebagian masyarakat yang kurang beruntung, kasus malpraktek baik pada operasi bedah umum maupun operasi bedah plastik dan kasus-kasus lainnya. Metro TV merespon hal ini dengan memberikan judul salah satu acara dialog Awas Hati-Hati, Orang Miskin Tidak Boleh Sakit pada tanggal 7 April 2012 (Kompasiana, 2012). Dengan adanya kasus Prita dan pemberitaan yang berkaitan dengan pelayanan rumah sakit maka hal ini menandakan bahwa pelayanan rumah sakit masih sarat dengan permasalahan yang harus segera dicari jalan keluarnya.

Dinyatakan oleh Hofstede (1994) dalam Trianingsih (2007) bahwa budaya organisasi berpengaruh terhadap kinerja organisasi dan budaya organisasi mencerminkan nilai-nilai dan keyakinan yang dimiliki oleh anggota organisasi. Budaya organisasi didalam organisasi meliputi keyakinan bersama, nilai-nilai hidup yang dianut, norma-norma perilaku, sikap, tata hubungan serta asumsi-asumsi yang secara implisit diterima dan secara eksplisit dimanifestasikan diseluruh jajaran organisasi. Budaya organisasi merupakan pola pemikiran, perasaan dan tindakan dari suatu kelompok sosial yang membedakan dengan kelompok sosial lainnya. Disinyalir bahwa budaya organisasi yang baik akan tercermin dari perilaku anggota organisasi, sehingga apabila budaya suatu rumah sakit baik maka akan terlihat dari pelayanan yang akan diberikan oleh pihak rumah sakit terhadap pasienpasiennya. Hal tersebut didukung oleh pernyataan dari Robbin (2003) bahwa budaya organisasilah yang membedakan antar organisasi yang satu dengan organisasi yang lain. Komitmen organisasi disinyalir juga berpengaruh terhadap kinerja organisasi, dijelaskan oleh Lekatompessy (2005) bahwa komitmen organisasi berkaitan dengan: (1) Keinginan yang kuat dan penerimaan atas tujuan dan nilainilai organisasi. (2) Kesediaan untuk berusaha yang sebesar-besarnya untuk organisasi (3) Keinginan yang pasti untuk mempertahankan keikutsertaan dalam organisasi. Dengan kata lain karyawan yang 
mempunyai komitmen terhadap organisasi akan memberikan kinerja yang baik ketimbang yang tidak berkomitmen. Kinerja organisasi dari suatu lembaga RS sebagaimana lembaga-lembaga publik lainnya tentu menuntut akuntabilitas publik Disinyalir keberadaan RS swasta memerlukan akuntabilitas publik dan kinerjanya amat tergantung pada tingkat akuntabilitas publik yang diterimanya. Menurut Mardiasmo (2004), akuntabilitas publik adalah kewajiban pihak pemegang amanah (agent) untuk memberikan pertanggungjawaban, menyajikan, melaporkan, dan mengungkapkan segala aktivitas dan kegiatan yang menjadi tanggungjawabnya kepada pihak pemberi amanah (principal) yang memiliki hak dan kewenangan untuk meminta pertanggungjawaban tersebut". Berdasarkan uraian diatas maka dapat disusun hipotesa sebagai berikut:

H1 : Terdapat pengaruh positif dan signifikan antara budaya organisasi terhadap kinerja organisasi RS Swasta di Jakarta Barat

$\mathrm{H} 2$ : Terdapat pengaruh positif dan signifikan antara komitmen organisasi terhadap kinerja organisasi RS Swasta di Jakarta Barat

H3 : Terdapat pengaruh positif dan signifikan antara akuntabilitas publik terhadap kinerja organisasi RS Swasta di Jakarta Barat

H4 : Terdapat pengaruh positif dan signifikan antara budaya organisasi, komitmen organisasi dan akuntabilitas publik secara bersama-sama terhadap kinerja organisasi RS Swasta di Jakarta Barat

\section{METODE}

Metode yang digunakan pada penelitian ini adalah metode survei, di mana metode pengumpulan data primer dengan menggunakan pertanyaan lisan dan tulisan dalam Indriantono dan Supomo (1999). Survei dilakukan dengan mendatangi langsung RS Swasta yang dijadikan objek penelitian. Sesuai dengan kriteria metode survei diperlukan hubungan langsung peneliti dengan responden. Hal tersebut diwujudkan dengan menggunakan instrumen kuesioner.

Penelitian ini mengenai analisis pengaruh budaya organisasi, komitmen organisasi dan akuntabilitas publik terhadap kinerja RS Swasta di Jakarta Barat, maka berdasarkan karakteristik permasalahannya penelitian ini tergolong bersifat penelitian asosiatif, yaitu penelitian yang dilakukan untuk menguji hubungan dan pengaruh antar dua atau tiga variabel penelitian. Berkaitan dengan hubungan ini menurut Sugiyono (2007) ada tiga macam hubungan, yaitu hubungan simetris, hubungan kausal dan hubungan resiprokal. Penelitian ini digolongkan sebagai penelitian kausal.

Populasi penelitian ini adalah keseluruhan RS yang bergerak di bidang jasa pelayanan kesehatan di wilayah Jakarta Barat. Dijelaskan oleh Sugiyono (2007) populasi adalah wilayah generalisasi yang terdiri atas objek/subjek yang mempunyai kualitas dan karakteristik tertentu yang ditetapkan oleh peneliti untuk dipelajari dan kemudian ditarik kesimpulannya. Pemilihan sampel dilakukan dengan metode purposive random sampling dengan teknik pertimbangan tertentu, yaitu dengan mempertimbangkan lamanya bekerja dan pendidikan minimal S1 untuk Direktur RS Swasta, Manajer Keuangan, Manajer Marketing, Manajer Litbang/Manajer SDM yang ditunjuk oleh Manajemen RS Swasta.

Untuk penentuan ukuran sampel, karena populasi yang dipilih seluruhnya merupakan orangorang yang bekerja di rumah sakit maka dapat disimpulkan bahwa populasi bisa dianggap homogen. Sehingga menurut Sugiyono (2007) apabila pupulasinya bersifat homogen, maka jumlah sampel yang diperlukan 1\% saja sudah bisa mewakili. Sampel yang dipilih dan dikirimkan kuestioner sebanyak 12 RS Swasta yang ada di wilayah Jakarta Barat meliputi RS.PI, RS. SKJ, RS. RT, RSIA. HDM. RS. PMK. RS. MPH. RS. BM, RS. MHTC, RS. PIKKT, RS. HK, RS. KD dan RS. BSM. Namun yang mengembalikan kuestioner hanya $10 \mathrm{RS}$ maka berdasarkan teori tersebut peneliti mengasumsikan jika masing-masing rumah sakit mempunyai karyawan 400 orang maka, akan diperoleh empat responden. 
Dengan demikian peneliti dapat menentukan jumlah sampel untuk setiap rumah sakit sebanyak empat orang yang mewakili bidangnya masing-masing sehingga berdasarkan kuestioner yang masuk ada sebanyak 40 responden.. Berikut disajikan instrumen penelitian yang meliputi : variabel, dimensi dan indikator penelitian.

Tabel 1 Instrumen Penelitian

\begin{tabular}{|c|c|c|}
\hline Variabel & Dimensi & Indikator \\
\hline \multirow[t]{4}{*}{$\begin{array}{l}\text { Budaya Organisasi } \\
\left(\mathrm{X}_{1}\right)\end{array}$} & Orientasi pada rincian & $\begin{array}{l}\text { - Job deskription yang jelas } \\
\text { - Prosedur yang digunakan }\end{array}$ \\
\hline & Orientasi pada hasil & $\begin{array}{l}\text { - Tujuan yang dltetapkan } \\
\text { - Hasil yang dicapai }\end{array}$ \\
\hline & Orientasi pada orang & $\begin{array}{l}\text { - Pelayanan kepada orang } \\
\text { - Perhatian kepada orang }\end{array}$ \\
\hline & Orientasi pada tim & $\begin{array}{l}\text { - Pelayanan kepada tim } \\
\text { - Perhatian kepada tim }\end{array}$ \\
\hline \multirow[t]{3}{*}{$\begin{array}{l}\text { Komitmen Organisasi } \\
\left(\mathrm{X}_{2}\right)\end{array}$} & Affective Commitment & $\begin{array}{l}\text { - Sense of belonging } \\
\text { - } \quad \text { Emotional attached } \\
\text { - } \text { personal meaning }\end{array}$ \\
\hline & Continuance Commitment & $\begin{array}{l}\text { - Pilihan lain } \\
\text { - Benefit } \\
\text { - Biaya }\end{array}$ \\
\hline & Normatif Commitment & $\begin{array}{l}\text { - Keyakinan untuk loyal } \\
\text { - Keyakinan akan etika }\end{array}$ \\
\hline \multirow[t]{5}{*}{$\begin{array}{l}\text { Akuntabilitas Publik } \\
\left(\mathrm{X}_{3}\right)\end{array}$} & $\begin{array}{l}\text { Akuntabilitas Hukum dan } \\
\text { Kejujuran }\end{array}$ & $\begin{array}{l}\text { - Ketaatan pada peraturan yang ada } \\
\text { - Kejujuran } \\
\text { - Penghindaran/penyalahgunaan jabatan }\end{array}$ \\
\hline & Akuntabilitas Managerial & $\begin{array}{l}\text { - Kinerja yang dicapai } \\
\text { - Proses dalam organisasi }\end{array}$ \\
\hline & Akuntabilitas Program & $\begin{array}{l}\text { - Pencapaian program } \\
\text { - Alternative program } \\
\text { - Kualitas program }\end{array}$ \\
\hline & Akuntabilitas Kebijakan & $\begin{array}{l}\text { - Kebijakan yang diambil } \\
\text { - Kebijakan yang akan dicapai } \\
\text { - Tujuan kebijakan } \\
\text { - Sasaran kebijakan } \\
\text { - Stakeholder yang berpengaruh }\end{array}$ \\
\hline & Akuntabilitas Financial & $\begin{array}{l}\text { - Penggunaan keuangan } \\
\text { - Penggunaan anggaran } \\
\text { - Laporan keuangan }\end{array}$ \\
\hline \multirow{6}{*}{$\begin{array}{l}\text { Kinerja Organisasi } \\
\text { RS Swasta } \\
\text { (Y) }\end{array}$} & Perspektif Keuangan & - Posisi Operating Incomei \\
\hline & & $\begin{array}{l}\text { - Posisi Gross Margin } \\
\text { - Posisi Return On Equity (ROE) } \\
\text { - Posisi Return On Investment (ROI) } \\
\text { - Posisi Economic Value Added (EVA) }\end{array}$ \\
\hline & Perspektif Pelanggan & $\begin{array}{l}\text { a. Kelompok inti: } \\
\text { - Pangsa pasar } \\
\text { - Perolehan pelanggan baru } \\
\text { - Kemampuan mempertahankan pelanggan } \\
\text { - Fenomena kepuasan pelanggan } \\
\text { b. Kelompok Penundang: } \\
\text { - Atribut-atribut produk } \\
\text { - Hubungan dengan pelanggan } \\
\text { - Citra dan reputasi perusahaan }\end{array}$ \\
\hline & Perspektif Proses Bisnis Internal & $\begin{array}{l}\text { - Inovasi } \\
\text { - } \quad \text { Proses operasi } \\
\text { - } \text { Proses pelayanan purna jual }\end{array}$ \\
\hline & Perspektif Pembelajaran dan & - Kemampuan pekerja \\
\hline & Pertumbuhan & $\begin{array}{l}\text { - Kemampuan sistem informasi } \\
\text { - Motivasi pemberdayaan-keserasian }\end{array}$ \\
\hline
\end{tabular}


Uji kualitas data dilakukan untuk mengetahui kualitas data berdasarkan kuesioner yang diajukan kepada responden. Uji kualitas data meliputi; uji validitas dilakukan dengan menggunakan metode korelasi product moment Karl Pearson, dan uji reliabilitas dengan menggunakan metode Alpha Cronbach. Uji asumsi klasik dilakukan untuk mengetahui kelayakan dari variabel-variabel yang digunakan yang meliputi: uji normalitas, uji multikolinearitas dan uji heterokedastisitas. Uji hipotesa dilakukan untuk menguji pengaruh variabel independen terhadap variabel dependen, baik secara parsial maupun secara bersama-sama, yang meliputi: analisa korelasi, analisa regresi, uji signifikansi dan koefisien determinasi. Uji signifikansi regresi berganda terhadap hipotesis penelitian dengan menggunakan persamaan, adalah:

$$
\hat{\mathbf{Y}}=\mathbf{a}+\mathbf{b}_{1} \mathbf{X}_{1}+\mathbf{b}_{2} \mathbf{X}_{2}+\mathbf{b}_{3} \mathbf{X}_{3}+\varepsilon
$$

Untuk mencari koefisien regresi $a, b_{1}, b_{2}$, dan $b_{3}$ digunakan persamaan simultan sebagai berikut:

$$
\begin{aligned}
\text { 1. } \sum \mathrm{X} 1 \mathrm{Y}=\mathrm{b} 1 \sum \mathrm{X} 1^{2}+\mathrm{b} 2 \sum \mathrm{X} 1 \mathrm{X} 2+\mathrm{b} 3 \sum \mathrm{X} 1 \mathrm{X} 3 \\
\text { 2. } \sum \mathrm{X} 2 \mathrm{Y}=\mathrm{b} 1 \sum \mathrm{X} 1 \mathrm{X} 2+\mathrm{b} 2 \sum \mathrm{X}^{2} 2+\mathrm{b} 3 \sum \mathrm{X} 2 \mathrm{X} 3 \\
\text { 3. } \sum \mathrm{X} 3 \mathrm{Y}=\mathrm{b} 1 \sum \mathrm{X} 1 \mathrm{X} 3+\mathrm{b} 2 \sum \mathrm{X} 2 \mathrm{X} 3+\mathrm{b} 3 \sum \mathrm{X}^{2} 3 \\
-\quad \mathrm{a} \equiv \mathrm{Y}-\underline{\mathrm{b}} 1 \mathrm{X} 1-\underline{\mathrm{b} 2} \mathrm{X} 2-\mathrm{b} 3 \mathrm{X} 3
\end{aligned}
$$

Pengolahan data dilakukan dengan menggunakan SPSS (Statistical Package for the Social Sciences) for windows versi 17.

\section{HASIL DAN PEMBAHASAN}

\section{Hasil Uji Kualitas Data}

\section{Uji Validitas}

Hasil uji validitas terhadap variabel budaya organisasi (X1), komitmen organisasi (X2), akuntabilitas publik (X3) dan kinerja organisasi RS Swasta di Jakarta Barat (Y) disajikan dalam tabel sebagai berikut:

Tabel 2 Uji Validitas

\begin{tabular}{ccccc}
\hline Variabel & $\begin{array}{c}\text { Jumlah butir } \\
\text { pertanyaan dalam } \\
\text { kuestioner }\end{array}$ & $\begin{array}{c}\text { Pertanyaan valid } \\
\text { jika rhitung>rtabel }\end{array}$ & $\begin{array}{c}\text { Pertanyaan tidak } \\
\text { valid jika } \\
\text { rhitung }<\text { rtabel }\end{array}$ & Keterangan \\
\hline X1 & 28 & 22 & 6 & pertanyaan \\
X2 & 21 & 15 & 6 & tidak valid \\
X3 & 28 & 23 & 5 & tidak dapat \\
Y & 40 & 26 & 14 & dilakukan \\
& & & & pengujian \\
\hline
\end{tabular}

Sumber: Hasil olahan data primer 


\section{Uji Reliabilitas}

Hasil uji reliabilitas untuk Cronbach Alpha dengan menggunakan SPSS untuk budaya organisasi sebesar 0,880, komitmen organisasi sebesar 0,915, akuntabilitas public sebesar 0,906 dan kinerja organisasi RS Swasta sebesar 0,914. Nilai-nilai tersebut semuanya lebih besar dari kriteria Nunnally sebesar 0,60 , hal ini berarti bahwa semua hasil uji menunjukkan hasil yang reliable.

\section{Hasil Uji Asumsi Klasik}

\section{Uji Normalitas}

Hasil uji normalitas data budaya organisasi (X1) dengan menggunakan Kolmogorov-Smirnov dengan Asymp dan diketahui besarnya nilai Kolmogorov-Smirnov adalah 0,749 dengan Asymp.Sig (2tailed) 0,629 dimana hasil tersebut lebih besar dari $\alpha(0,05)$, sehingga dapat disimpulkan bahwa data memenuhi asumsi berdistribusi normal. Demikian pula uji normalitas data komitmen organisasi (X2) diperoleh nilai Kolmogorov- Smirnow 0,749 dengan signifikansi 0,629>0,05 maka dinyatakan bahwa komitmen organisasi memenuhi asumsi normalitas. Hasil uji normalitas data akuntabilitas publik (X3) diperoleh nilai Kolmogorov- Smirnow 0,571 dengan signifikansi 0,900>0,05 maka dinyatakan bahwa akuntabilitas publik juga memenuhi asumsi normalitas. Terakhir, untuk uji normalitas data budaya organisasi, komitmen organisasi dan akuntabilitas publik terhadap kinerja organisasi RS Swasta dengan menggunakan Kolmogorov-Smirnov dengan Asymp. Sig (2- tailed) diperoleh nilai 0,961 dimana hasil tersebut lebih besar dari $\alpha(0,05)$, sehingga dapat disimpulkan bahwa data berdistribusi normal.

\section{Uji Multikolinearitas}

Hasil uji multikolinearitas terhadap budaya organisasi, komitmen organisasi dan akuntabilitas publik terhadap kinerja organisasi RS Swasta diperoleh dengan menggunakan SPSS adalah sebagai berikut:

Tabel 3 Hasil Uji Multikolinearitas

\begin{tabular}{|c|c|c|c|c|c|c|c|c|}
\hline \multicolumn{9}{|c|}{ Coefficients $^{a}$} \\
\hline \multirow[b]{2}{*}{ Model } & & \multicolumn{2}{|c|}{$\begin{array}{l}\text { Unstandardized } \\
\text { Coefficients }\end{array}$} & \multirow{2}{*}{$\begin{array}{c}\text { Standardized } \\
\text { Coefficients } \\
\text { Beta } \\
\end{array}$} & \multirow[b]{2}{*}{$t$} & \multirow[b]{2}{*}{ Sig. } & \multicolumn{2}{|c|}{ Collinearity Statistics } \\
\hline & & B & Std. Error & & & & Tolerance & VIF \\
\hline 1 & (Constant) & 76.633 & 19.510 & & 3.928 & .000 & & \\
\hline & Budaya Organisasi & -.294 & .277 & -.208 & -1.065 & .294 & .523 & 1.914 \\
\hline & Komitmen Organisasi & -.345 & .251 & -.256 & -1.372 & .179 & .570 & 1.755 \\
\hline & Akuntabilitas Publik & .726 & .205 & .566 & 3.543 & .001 & .781 & 1.280 \\
\hline
\end{tabular}

Sumber: Hasil Olahan SPSS

Berdasarkan tabel 3 maka diketahui bahwa nilai VIF untuk budaya organisasi $\left(\mathrm{X}_{1}\right)$ adalah 1,914 , komitmen organisasi $\left(\mathrm{X}_{2}\right)$ adalah 1,755 , dan akuntabilitas publik $\left(\mathrm{X}_{3}\right)$ sebesar 1,280 . Semua nilai variabel tersebut berada di antara 1-10. Nilai cut off yang umum dipakai untuk menunjukkan adanya multikolonieritas adalah nilai tolerance $<0,10$ atau sama dengan nilai VIF $>10$, sehingga dapat disimpulkan bahwa tidak terjadi multikolinearitas antara variabel independen dalam model regresi.

\section{Hasil Uji Heterokedastisitas}

Berdasarkan hasil olahan data SPSS diketahui bahwa menurut metode Park Glejser diperoleh hasil berupa nilai sig untuk budaya organisasi (X1) adalah 0,294, komitmen organisasi (X2) adalah 0,179 , dan akuntabilitas publik sebesar 0,001 . Untuk hasil budaya organisasi, komitmen organisasi 
mempunyai nilai lebih besar dari nilai $\alpha(0,05)$, sehingga dapat disimpulkan bahwa variabel-variabel tersebut tidak terjadi heterokedastisitas. Sedangkan untuk akuntabilitas publik dengan nilai 0,001 dapat disimpulkan terjadi heterosiksitas.

\section{Hasil Uji Hipotesis}

\section{Uji Hipotesis 1}

H1 : Terdapat pengaruh yang positif dan signifikan antara budaya organisasi terhadap kinerja organisasi RS Swasta di Jakarta Barat.

Tabel 4 Korelasi Budaya Organidasi dengan Kinerja Organisasi

RS Swasta di Jakarta Barat

Model Summary
\begin{tabular}{|l|r|r|r|r|}
\hline Model & $\mathrm{R}$ & R Square & $\begin{array}{c}\text { Adjusted } \\
\text { R Square }\end{array}$ & $\begin{array}{c}\text { Std. Error of } \\
\text { the Estimate }\end{array}$ \\
\hline 1 & $.116^{\mathrm{a}}$ & .013 & -.013 & 12.001 \\
\hline
\end{tabular}
a. Predictors: (Constant), Budaya Organisasi
Sumber: Hasil Olahan SPSS

Tabel 4 menunjukan korelasi antara budaya organisasi terhadap kinerja Rumah Sakit Swasta di Jakarta Barat sebesar 0,116, hal ini berarti sangat rendah berdasarkan pedoman interpretasi koefisien korelasi menurut Sugiyono (2009).

Tabel 5 Hasil Regresi Budaya Organisasi terhadap Kinerja Organisasi RS Swastadi Jakarta Barat

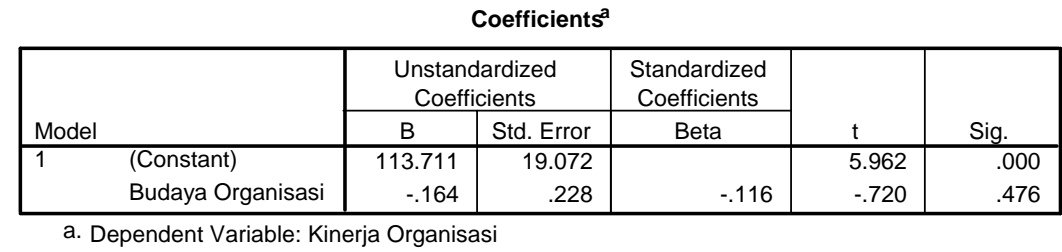

Sumber: Hasil Olahan SPSS

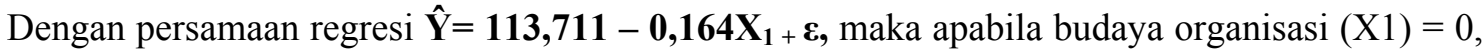
maka kinerja organisasi RS Swasta adalah sebesar 113,71. Koefisien regresi budaya organisasi $\left(\mathrm{X}_{1}\right)$ sebesar -0,164 menunjukan bahwa budaya organisasi $\left(\mathrm{X}_{1}\right)$ mempunyai berpengaruh negative terhadap kinerja organisasi RS Swasta di Jakarta Barat (Y). Standar error koefisien regresi budaya organisasi $\left(\mathrm{Sb}_{1}\right)$ sebesar 0,228 maka uji signifikansi regresi:

$$
\mathrm{t}_{\mathrm{o}}=\mathrm{b}_{1 / 2} \mathrm{Sb}_{1}=-0,164 / 0,228=-0,719
$$

Berdasarkan $t_{\text {table }} t$ untuk signifikansi $5 \%$ dengan $\mathrm{df}=38$ diperoleh nilai 2,024. Maka karena to $(-0,719)<t_{\text {tabel }}(2,024)$, dan dengan signifikansi 0,476 berada jauh diatas $\alpha=0,05$, maka Ho diterima dan Ha ditolak yang berarti bahwa ada tidak ada pengaruh yang signifikan antara budaya organisasi $\left(\mathrm{X}_{1}\right)$ terhadap kinerja organisasi (Y) Rumah Sakit Swasta di Jakarta Barat. Pada nilai $r$ sebesar 0,116 maka koefisien determinasinya adalah sebesar 0,013 sehingga perhitungan koefisien determinasinya adalah $\mathrm{KD}=\mathrm{r}^{2} \times 100 \%=0,116^{2} \times 100 \%=1.346 \%$. 
Budaya organisasi mempengaruhi kinerja organisasi RS Swasta di Jakarta Barat sebesar 1,346\% sisanya $98,654 \%$ dipengaruhi oleh faktor lain. Nilai ini menunjukkan kecilnya pengaruh budaya organisasi terhadap kinerja organisasi RS Swasta di Jakarta Barat yaitu hanya sebesar 1,346\%.

\section{Uji Hipotesis 2}

H1 : Terdapat pengaruh yang positif dan signifikan antara komitmen organisasi terhadap kinerja organisasi RS Swasta di Jakarta Barat.

Tabel 6 Korelasi Komitmen Organidasi dengan Kinerja Organisasi

RS Swasta di Jakarta Barat

\begin{tabular}{|c|c|c|c|c|}
\hline \multicolumn{5}{|c|}{ Model Summary } \\
\hline Model & $\mathrm{R}$ & R Square & $\begin{array}{l}\text { Adjusted } \\
\text { R Square }\end{array}$ & $\begin{array}{l}\text { Std. Error of } \\
\text { the Estimate }\end{array}$ \\
\hline 1 & $.182^{\mathrm{a}}$ & .033 & .008 & 11.882 \\
\hline
\end{tabular}

a. Predictors: (Constant), Komitmen Organisasi

Sumber: Hasil Olahan SPSS

Tabel 6 menunjukan bahwa korelasi komitmen organisasi terhadap kinerja Rumah Sakit Swasta di Jakarta Barat sebesar 0,182, hal ini berarti sangat rendah, berdasarkan pedoman interpretasi koefisien korelasi menurut Sugiyono (2009).

Tabel 7 Hasil Regresi Komitmen Organisasi terhadap Kinerja Organisasi RS Swasta di Jakarta Barat

\begin{tabular}{|c|c|c|c|c|c|c|}
\hline \multicolumn{7}{|c|}{ Coefficients $^{a}$} \\
\hline \multirow[b]{2}{*}{ Model } & & \multicolumn{2}{|c|}{$\begin{array}{l}\text { Unstandardized } \\
\text { Coefficients }\end{array}$} & \multirow{2}{*}{$\begin{array}{l}\text { Standardized } \\
\text { Coefficients } \\
\text { Beta }\end{array}$} & \multirow[b]{2}{*}{$\mathrm{t}$} & \multirow[b]{2}{*}{ Sig. } \\
\hline & & B & Std. Error & & & \\
\hline & (Constant) & 111.173 & 9.939 & & 11.185 & .000 \\
\hline & Komitmen Organisasi & -.244 & .215 & -.182 & -1.140 & .262 \\
\hline
\end{tabular}

a. Dependent Variable: Kinerja Organisasi

Sumber: Hasil Olahan SPSS

Dengan persamaan regresi $\hat{\mathbf{Y}}=\mathbf{1 1 1}, \mathbf{1 7 3}-\mathbf{0 , 2 4 4 X _ { 1 }} \boldsymbol{\varepsilon}$ maka apabila komitmen organisasi $(X 2)$ bernilai nol maka kinerja organisasi RS Swasta di Jakarta Barat (Y) sebesar 111,173. Koefisien regresi variabel komitmen organisasi (X2) menunjukkan bahwa komitmen organisasi (X2) mempunyai berpengaruh negative terhadap kinerja organisasi RS Swasta di Jakarta Barat (Y). Standar error koefisien regresi komitmen organisasi $\left(\mathrm{Sb}_{1}\right)$ sebesar 0,215 maka uji signifikansi regresi dihutung sebagai berikut adalah:

$$
\mathrm{t}_{\mathrm{o}}=\mathrm{b}_{2 /} \mathrm{Sb}_{2}=-0,244 / 0,215=-1,135
$$

Berdasarkan $t_{\text {table }} t$ untuk signifikansi $5 \%$ dengan $\mathrm{df}=38$ diperoleh nilai 2,024. Maka karena to $(-1,135)<t_{\text {tabel }}(2,024)$, dan dengan signifikansi 0,262 berada jauh diatas $\alpha=0,05$, maka Ho diterima dan Ha ditolak yang berarti bahwa tidak ada pengaruh yang signifikan antara komitmen organisasi $\left(\mathrm{X}_{2}\right)$ terhadap kinerja organisasi $(\mathrm{Y})$ Rumah Sakit Swasta di Jakarta Barat. Dengan nilai r sebesar 0,182 maka koefisien determinasinya sebesar 0,033 diperoleh dari:

$$
\mathrm{KD}=\mathrm{r}^{2} \times 100 \%=0,182^{2} \times 100 \%=3.312 \%
$$


Komitmen organisasi mempengaruhi kinerja organisasi RS Swasta di Jakarta Barat sebesar $3.312 \%$ sisanya $96,688 \%$ dipengaruhi oleh faktor lain. Nilai ini menunjukkan kecilnya pengaruh komitmen organisasi terhadap kinerja organisasi RS Swasta di Jakarta Barat yaitu hanya sebesar $3,312 \%$

\section{Uji Hipotesis 3}

H3 : Terdapat pengaruh yang positif dan signifikan antara akuntabilitas public terhadap kinerja organisasi RS Swasta di Jakarta Barat.

Tabel 8 Korelasi Akuntabilitas Publik dengan Kinerja Organisasi

RS Swasta di Jakarta Barat

\begin{tabular}{|l|r|r|r|r|}
\multicolumn{7}{c}{ Model Summary } \\
\hline Model & R & R Square & $\begin{array}{c}\text { Adjusted } \\
\text { R Square }\end{array}$ & $\begin{array}{c}\text { Std. Error of } \\
\text { the Estimate }\end{array}$ \\
\hline 1 & $.375^{\mathrm{a}}$ & .141 & .118 & 11.200 \\
\hline
\end{tabular}

a. Predictors: (Constant), Akuntabilitas Publik

Sumber: Hasil Olahan SPSS

Tabel 8 menunjukan korelasi antara akuntabilitas publik terhadap kinerja organisasi RS Swasta sebesar 0,375, hal ini berarti bahwa hubungan antara akuntabilitas publik dengan kinerja organisasi RS Swasta di Jakarta Barat rendah, berdasarkan pedoman interpretasi koefisien korelasi menurut Sugiyono (2009).

Tabel 9 Hasil Regresi Akuntabilitas Publik terhadap Kinerja Organisasi RS Swasta Jakarta Barat

Coefficients $\mathbf{s}^{\mathrm{a}}$

\begin{tabular}{|rl|r|r|r|r|r|}
\hline \multirow{2}{*}{ Model } & \multicolumn{2}{|c|}{$\begin{array}{c}\text { Unstandardized } \\
\text { Coefficients }\end{array}$} & $\begin{array}{c}\text { Standardized } \\
\text { Coefficients }\end{array}$ & & \\
\cline { 2 - 5 } & & \multicolumn{1}{|c|}{ B } & Std. Error & Beta & \multicolumn{1}{c|}{ t } & Sig. \\
\hline 1 & (Constant) & 57.851 & 16.998 & & 3.403 & .002 \\
& Akuntabilitas Publik & .482 & .193 & .375 & 2.496 & .017 \\
\hline
\end{tabular}

a. Dependent Variable: Kinerja Organisasi

Sumber: Hasil Olahan SPSS

Dengan persamaan regresi maka apabila akuntabilitas publik (X3) bernilai nol maka kinerja organisasi RS Swasta di Jakarta Barat (Y) sebesar 57,851. Koefisien regresi variabel akuntabilitas publiki (X3) menunjukkan nilai positif sebesar 0,482 yang diartikan akuntabiitas publik (X3) mempunyai berpengaruh positive terhadap kinerja organisasi RS Swasta di Jakarta Barat (Y). Standar error koefisien regresi akuntabilitas publik $\left(\mathrm{Sb}_{3}\right)$ sebesar 0,193 maka hasil uji signifikansi regresi:

$$
\mathrm{t}_{\mathrm{o}}=\mathrm{b}_{3} / \mathrm{Sb}_{3}=0,482 / 0,193=2,497
$$

Berdasarkan $t_{\text {table }}$ untuk signifikansi $5 \%$ dengan $\mathrm{df}=38$ diperoleh nilai 2,204. Karena $t_{\mathrm{o}}$ $(2,497)>t_{\text {tabel }}(2,204)$, dan dengan signifikansi 0,017 berada di bawah $\alpha=0,05$, maka Ha diterima dan Ho ditolak, berarti bahwa ada pengaruh yang signifikan antara akuntabilitas publik $\left(\mathrm{X}_{3}\right)$ terhadap kinerja organisasi (Y) Rumah Sakit Swasta di Jakarta Barat. Pada nilai $r$ sebesar 0,375 dengan koefisien determinasi sebesar 0,141 yang diperoleh dari perhitungan:

$$
\mathrm{KD}=\mathrm{r}^{2} \times 100 \%=0,375^{2} \times 100 \%=14,063 \%
$$


Akuntabilitas publik mempengaruhi kinerja Rumah Sakit Swasta di Jakarta Barat sebesar $14,063 \%$, sedangkan sisanya dipengaruhi oleh faktor lain. Nilai ini menunjukkan pengaruh akuntabilitas publik terhadap kinerja organisasi yaitu sebesar 14,063\%.

\section{Uji Hipotesis 4}

H4 : Terdapat pengaruh yang positif dan signifikan antara komitmen organisasi, budaya organisasi, dan akuntabilitas publik terhadap kinerja organisasi Rumah Sakit Swasta di Jakarta Barat.

Tabel 10 Korelasi Budaya Organisasi, Komitmen Organisasi dan Akuntabilitas Publik terhadap Kinerja Organisasi RS Swasta

Model Summary

\begin{tabular}{|l|r|r|r|r|}
\hline Model & \multicolumn{1}{|c|}{ R } & R Square & $\begin{array}{c}\text { Adjusted } \\
\text { R Square }\end{array}$ & $\begin{array}{r}\text { Std. Error of } \\
\text { the Estimate }\end{array}$ \\
\hline 1 & $.532^{\mathrm{a}}$ & .283 & .223 & 10.512 \\
\hline
\end{tabular}

a. Predictors: (Constant), Akuntabilitas Publik, Komitmen Organisasi, Budaya Organisasi

\section{Sumber: Hasil Olahan SPSS}

Tabel 10 menunjukkan korelasi antara budaya organisasional $\left(\mathrm{X}_{1}\right)$, komitmen organisasi $\left(\mathrm{X}_{2}\right)$, akuntabilitas publik $\left(\mathrm{X}_{3}\right)$ terhadap kinerja organisasi RS Swasta di Jakarta Barat sebesar 0,532, hal ini berarti bahwa hubungan antara $\mathrm{X}_{1}, \mathrm{X}_{2}, \mathrm{X}_{3}$ terhadap $\mathrm{Y}$ adalah tingkat sedang berdasarkan nilai 0,40 0,59 dalam pedoman interpretasi koefisien korelasi Sugiyono (2009).

Tabel 11 Hasil Regresi Budaya Organisasi, Komitmen Organisasi dan Akuntabilitas Publik terhadap Kinerja Orgainsasi RS Swasta di Jakarta Barat

\begin{tabular}{|c|c|c|c|c|c|c|}
\hline \multicolumn{7}{|c|}{ Coefficients $^{a}$} \\
\hline \multirow[b]{2}{*}{ Model } & & \multicolumn{2}{|c|}{$\begin{array}{l}\text { Unstandardized } \\
\text { Coefficients }\end{array}$} & \multirow{2}{*}{$\begin{array}{c}\begin{array}{c}\text { Standardized } \\
\text { Coefficients }\end{array} \\
\text { Beta }\end{array}$} & \multirow[b]{2}{*}{$\mathrm{t}$} & \multirow[b]{2}{*}{ Sig. } \\
\hline & & B & Std. Error & & & \\
\hline & (Constant) & 76.633 & 19.510 & & 3.928 & .000 \\
\hline & Budaya Organisasi & -.294 & .277 & -.208 & -1.065 & .294 \\
\hline & Komitmen Organisasi & -.345 & .251 & -.256 & -1.372 & .179 \\
\hline & Akuntabilitas Publik & .726 & .205 & .566 & 3.543 & .001 \\
\hline
\end{tabular}

Sumber: Hasil Olahan SPSS

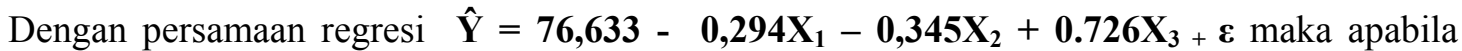
budaya organisasi $\left(\mathrm{X}_{1}\right)$, komitmen organisasi $\left(\mathrm{X}_{2}\right)$, akuntabilitas publik $\left(\mathrm{X}_{3}\right)$ bernilai nol, maka kinerja organisasi (Y) akan sebesar 76,633. Koefisien regresi variabel budaya organisasi $\left(\mathrm{X}_{1}\right)$, menunjukkan nilai negatif sebesar $-0,294$, ini berarti semakin tinggi budaya organisasi $\left(X_{1}\right)$ maka akan semakin rendah kinerja (Y) Rumah Sakit Swasta di Jakarta Barat. Koefisien regresi variabel komitmen organisasi $\left(\mathrm{X}_{2}\right)$, menunjukkan nilai negatif sebesar $-0,345$, ini berarti semakin tinggi komitmen organisasi $\left(\mathrm{X}_{2}\right)$ maka akan semakin rendah kinerja organisasi $(\mathrm{Y})$. Koefisien regresi variabel akuntabilitas publik $\left(\mathrm{X}_{3}\right)$, menunjukkan nilai positif sebesar 0,726, ini berarti semakin tinggi akuntabilitas publik $\left(\mathrm{X}_{3}\right)$, maka akan semakin tinggi pula kinerja (Y) Rumah Sakit Swasta di Jakarta Barat. 
Tabel 12 Regression Residual

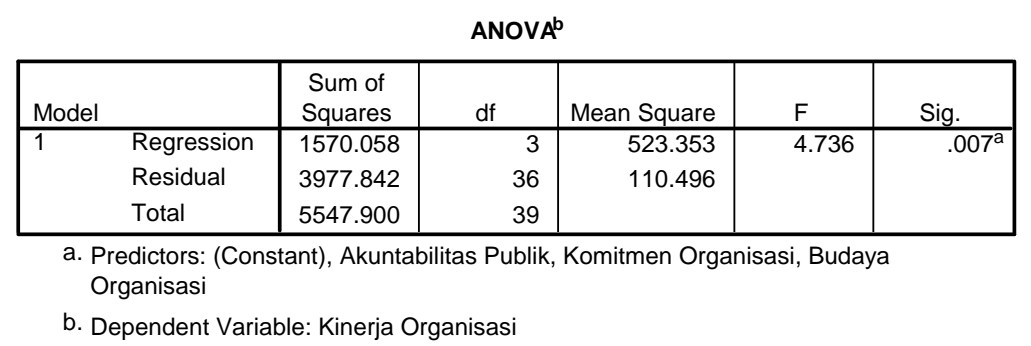

Sumber: Hasil Olahan SPSS

Dari tabel 12 diperolehi nilai $\mathrm{F}_{\text {hitung }}$ sebesar 4,736 $>\mathrm{F}$ tabel sebesar 2,85 dengan didasarkan pada $\mathrm{dk}$ pembilang $=3$ (jumlah variabel independen) dan $\mathrm{dk}$ penyebut $=36$ (jumlah sampel dikurang jumlah variabel independen dikurang 1). Dengan signifikansi 0,007 berada jauh di bawah 0,05 , maka Ha diterima dan Ho ditolak, berarti secara bersama-sama variabel budaya organisasi $\left(\mathrm{X}_{1}\right)$, komitmen organisasi $\left(\mathrm{X}_{2}\right)$ dan akuntabilitas publik $\left(\mathrm{X}_{3}\right)$ mempunyai pengaruh yang signifikan terhadap kinerja organisasi $(\mathrm{Y})$. Dengan nilai $\mathrm{r}$ sebesar 0,532 maka diperoleh koefisien determinasi sebesar 0,283 :

$$
\mathrm{KD}=\mathrm{r}^{2} \times 100 \%=0,532^{2} \times 100 \%=28,302 \%
$$

Dengan hasil tersebut menunjukan budaya organisasi $\left(\mathrm{X}_{1}\right)$, komitmen organisasi $\left(\mathrm{X}_{2}\right)$ dan akuntabilitas publik $\left(\mathrm{X}_{3}\right)$ secara bersama-sama mempengaruhi kinerja Rumah Sakit Swasta di Jakarta Barat sebesar $28,302 \%$ sedangkan sisanya $71,698 \%$ dipengaruhi oleh faktor lain. Penelitian ini bertujuan untuk menganalisis pengaruh budaya organisasi, komitmen organisasi dan akuntabilitas publik terhadap kinerja organisasi RS Swasta di Jakarta Barat. Penelitian sebelumnya pernah dilakukan oleh Prasetyono dan Kompyurini (2007) dengan mengambil sampel dan populasi Rumah Sakit Daerah di Jawa Timur. Hasil analisis hipotesis pertama diperoleh $t_{0}-0,719<t_{\text {tabel }} 2,024$ dan dengan signifikansi 0,476 berada jauh diatas $\alpha=0,05$, maka disimpulkan tidak terdapat pengaruh yang signifikan antara budaya organisasi terhadap kinerja Rumah Sakit Swasta di Jakarta Barat. Hasil penelitian ini didukung penelitian yang dilakukan oleh Trisnaningsih (2007), namun hasil penelitian ini berlawanan dengan temuan Flamholtz dan Naraziman (2005). Perbedaan hasil penelitian ini dengan sebelumnya disebabkan oleh lingkungan kehidupan responden dan kebijakan pelayanan RS Swasta yang berbeda beda. Dengan adanya kemacetan lalu lintas menjadikan orang mudah stress dan pelayananpun jadi kurang maksimal. Ini sesuai dengan pendapat Tjiptono (2000) dalam Kompyurini (2007), bahwa kualitas pelayanan dipengaruhi beberapa faktor yang salah satunya adalah budaya organisasi yang ditandai dengan adanya ada beberapa rumah sakit berupaya meningkatkan budaya organisasi dengan melakukan berbagai ritual dan seremoni secara rutin. Hal tersebut senada dengan pendapat Luthans (1995) dalam Sopiah (2008), yang menyatakan bahwa beberapa langkah sosialisasi dapat membantu dan mempertahankan budaya organisasi antara lain melalui seleksi calon karyawan, penempatan, pendalaman bidang pekerjaan, penilaian kinerja dan pemberian penghargaan, penanaman kesetiaan pada nilai-nilai luhur, perluasan cerita dan berita, pengakuan kinerja dan promosi. Hasil penelitian ini menunjukkan bahwa kinerja Rumah Sakit Swasta di Jakarta Barat akan dapat lebih optimal jika didukung oleh budaya organisasi yang baik. Seperti yang dikemukaan Kotter dan Heskett (1992) dalam Pabudu (2005) bahwa, budaya perusahaan dapat mempunyai dampak yang berarti terhadap kinerja ekonomi jangka panjang, budaya perusahaan akan menjadi faktor penting untuk menentukan keberhasilan atau kegagalan perusahaan dalam di masa depan.

Analisis untuk hipotesis kedua diperoleh $t_{\text {table }}$ untuk signifikansi $5 \%$ dengan $\mathrm{df}=38$ diperoleh nilai 2,024. Karena $t_{0}(-1,135)<t_{\text {tabel }}(2,024)$ dan dengan signifikansi 0,262 berada jauh diatas $\alpha=0,05$ sehingga dapat disimpulkan tidak terdapat pengaruh yang positif dan signifikan antara komitmen 
organisasi terhadap kinerja Rumah Sakit Swasta di Jakarta Barat. Hasil penelitian ini berlawanan dengan penelitian Meyer et al. (1989), Siders et al. (2001) dalam Trisnaningsih (2007). Temuan yang sama diperoleh dari hasil penelitian Somers dan Bimbaum (1998) dalam Trisnaningsih (2007). Hal ini dapat disebabkan oleh banyak faktor seperti lingkungan tempat responden dijadikan sampel. Mengingat banyaknya rumah sakit yang ada di Jakarta ataupun tempat pelayanan kesehatan yang sejenis lainnya sebagai pilihan untuk berkarir. Berdasarkan hasil kuesioner diketahui banyak responden yang menginginkan pindah kerja bila ada tawaran yang lebih baik atau tidak berpikir untuk bekerja sebagai pegawai RS Swasta selamanya. Hal tersebut sangat mungkin terjadi mengingat tempat populasi dan sampel diambil dari kota besar seperti Jakarta. Adanya komitmen dapat menjadi pendorong seseorang untuk bekerja lebih baik atau malah sebaliknya menyebabkan seseorang justru meninggalkan pekerjaannya karena mementingkan komitmen yang lain. Komitmen yang tepat akan memberikan motivasi yang tinggi dan memberikan dampak positif terhadap kinerja suatu pekerjaan (Trisnaningsih, 2007). Robbins (1989) dalam Sopiah (2008) menyatakan komitmen organisasi sebagai suatu sikap yang merefleksikan perasaan suka atau tidak suka dari karyawan terhadap organisasi.

Analisis hipotesis ketiga berdasarkan $t_{\text {table }}$ untuk signifikansi $5 \%$ dengan $\mathrm{df}=38$ diperoleh nilai 2,024. Karena $t_{\mathrm{o}}(2,497)>t_{\text {tabel }}(2,024)$, dan dengan signifikansi 0,017 berada jauh dibawah $\alpha=$ 0,05 sehingga dapat disimpulkan bahwa terdapat pengaruh yang positif dan signifikan antara akuntabilitas publik terhadap kinerja Rumah Sakit Swasta di Jakarta Barat. Hasil penelitian ini mendukung penelitian yang dilakukan Kompyurini (2007) menghasilkan, antara akuntabilitas dengan kualitas kerja memiliki hubungan yang positif untuk kompleksitas pekerjaan rendah. Tetapi untuk kompleksitas pekerjaan tinggi, akuntabilitas tidak memiliki hubungan positif dengan kualitas hasil kerja. Dari penelitian tersebut diatas dapat disimpulkan bahwa akuntabilitas publik ikut berperan dalam mewujudkan terciptanya kinerja sebuah rumah sakit yang baik. Karena tuntutan akuntabilitas publik mengharuskan organisasi atau perusahaan yang bergerak disektor publik lebih menekankan pertanggungjawaban kepada masyarakat luas. Kepercayaan dari masyarakat mutlak diperlukan untuk menjaga eksistensi suatu organisasi yang menunjukkan kinerja lembaga sektor publik dalam hal ini rumah sakit swasta berjalan dengan baik. Oleh sebab itu untuk mencapai kinerja yang optimal pada sektor publik diperlukan dukungan pada penciptaan transparasi, akuntabilitas publik dan pengukuran efisiensi dan efektivitas (UNDP Report, 2003; Wold Bank, 2003 dalam Kumpyurini, 2007).

Hasil analisis hipotesis keempat diperoleh nilai $F_{\text {hitung }}$ sebesar 4,736 $>F_{\text {tabel }}$ sebesar 2,85 dengan didasarkan pada dk pembilang $=3$ (jumlah variabel independen) $\mathrm{dan} \mathrm{dk}$ penyebut $=36$ (jumlah sampel dikurang jumlah variabel independen dikurang 1). Dengan signifikansi 0,007 berada jauh di bawah 0,05 . Berdasarkan hasil ini, maka hipotesis keempat terdapat pengaruh yang positif dan signifikan antara budaya organisasi, komitmen organisasi dan akuntabilitas publik terhadap kinerja Rumah Sakit Swasta di Jakarta Barat diterima. Hasil penelitian sebelumnya oleh Kompyurini (2007), diperoleh hasil budaya organisasi, komitmen organisasi, akuntabilitas publik secara simultan berpengaruh positif dan signifikan terhadap kinerja RSD dalam kategori kuat. Hasil penelitian ini mengindikasikan bahwa kinerja Rumah Sakit Swasta di Jakarta Barat belum optimal. Hal ini dapat dilihat dari uji pengaruh yang menghasilkan nilai kecil. Sehingga dapat disimpulkan kinerja Rumah Sakit Swasta di Jakarta Barat akan dapat lebih optimal jika budaya organisasi, komitmen organisasi dan akuntabilitas publik dapat terwujud dengan baik. Budaya organisasi dan komitmen organisasi yang baik akan menciptakan iklim kerja yang baik pula, sehingga akan tercermin dari pelayanaan yang akan diberikan kepada masyarakat. Sehingga tidak salah jika Schein (1984) dalam Kompyurini (2007), mengungkapkan bahwa banyak karya akhir-akhir ini berpendapat tentang peran kunci budaya organisasi untuk mencapai keunggulan organisasi. Budaya organisasi baik secara langsung maupun tidak langsung akan berpengaruh terhadap komitmen organisasi dan kinerja. 


\section{SIMPULAN}

Budaya organisasi tidak mempunyai pengaruh yang signifikan terhadap kinerja RS Swasta di Jakarta Barat. Penelitian ini mendukung hasil penelitian Trisnaningsih (2007), pada penelitiannya diperoleh hasil nilai $t_{\text {hitung }} 0,501<\mathrm{t}_{\text {tabel }} 1,96$ dan nilai $\mathrm{p}$ lebih besar dari $0,05(0,616>0,05)$. Komitmen organisasi tidak mempunyai pengaruh yang signifikan terhadap kinerja RS Swasta di Jakarta Barat. Penelitian ini mendukung hasil penelitian yang dilakukan oleh Wijayanti (2008), di mana dari penelitiannya diperoleh nilai $t_{\text {hitung }}(-0,656)>t_{\text {tabel }}(-2,069)$ dengan nilai signifikansi sebesar 0,520 lebih besar dari $\alpha=0,05$.

Akuntabilitas publik mempunyai pengaruh yang signifikan terhadap kinerja Rumah Sakit Swasta di Jakarta Barat. Penelitian ini mendukung hasil penelitian yang dilakukan oleh Mardisar (2007), dari hasil penelitiannya menunjukkan bahwa nilai $\beta X_{1}$ (akuntabilitas) positif dan signifikan ( $\beta$ $=2.145, \mathrm{t}=14.784, \mathrm{p}<0.001)$. Budaya organisasi, komitmen organisasi dan akuntabilitas publik secara bersama-sama atau simultan mempunyai pengaruh yang signifikan terhadap kinerja Rumah Sakit Swasta di Jakarta Barat. Penelitian ini mendukung hasil penelitian yang dilakukan oleh Kompyurini (2007), yaitu besarnya pengaruh secara simultan dalam kategori sangat kuat yaitu sebesar $81,6 \%$, sedangkan $18,4 \%$ dipengaruhi variabel lain yang tidak di teliti.

Dalam penelitian ini, masih ada keterbatasan-keterbatasan yang mempengaruhi hasil dari. Penelitian yaitu hanya mengambil sampel yang terbatas yaitu Rumah Sakit Swasta yang ada di wilayah Jakarta Barat sehingga hasil penelitian ini belum dapat dijadikan kesimpulan terhadap kinerja rumah sakit swasta maupun rumah sakit pemerintah di tempat lain. Penelitian ini juga hanya menggunakan variabel budaya organisasi, komitmen organisasi dan akuntabilitas publik sebagai variabel dependen dan kinerja organisasi RS Swasta sebagai variabel terikat sehingga masih perlu ditambahkan variabel-variabel lain, baik dari lingkungan internal maupun eksternal.

Berdasarkan adanya keterbatasan-keterbatasan diatas maka peneliti menyarankan untuk penelitian berikutnya untuk memperluas objek penelitian bukan hanya terbatas pada Rumah Sakit Swasta yang ada di wilayah Jakarta Barat saja tetapi ditambahkan juga rumah sakit lainnya, baik rumah sakit swasta maupun rumah sakit pemerintah yang di pusat maupun di daerah.. Menambah variabel penelitian yang belum sempat dikemukakan dan belum sempat diangkat ke dalam penelitian, antara lain lingkungan internal organisasi, lingkungan eksternal organisasi, struktur organisasi, gaya kepemimpinan, pengendalian internal dan lain sebagainya.

\section{DAFTAR PUSTAKA}

Flamholtz, E., Narasimhan, R. K. (2005). Differential Impact of Cultural Elements on Financial Performance. European Management Journal, (23): 50-64

Indriantoro, N., Supomo, B. (1999). Metodologi Penelitian Bisnis: Untuk Akuntansi dan Manajemen. Edisi 1. Yogyakarta: BPFE.

Kompas.com. (2009). Bisakah rumah sakit belajar dari Kasus Prita, diakses pada t 17 Juni 2009 dari http://bola.kompas.com/read/2009/06/15/21114790/bisakah.rumah.sakit.belajar.dari.kasus.pr ita

Lekatompessy, J. E. (2005). Analisis Variabel-variabel Anteseden dan Konsekuensi OrganizationalProfessional Conflict Akuntan di KAP dan Industri. Jurnal Riset Akuntansi Indonesia, 8(2): $158-174$. 
Luthans, F. (1995). Organisational Behaviour, Seventh Edition ed. Singapura: Mcgraw Hill Book Company

Mardiasmo. (2004). Akuntansi Sektor Publik, Edisi II. Yogyakarta: Penerbit Andi,.

Mardisar, D., Sari, R. N. (2007). Pengaruh Akuntabilitas dan Pengetahuan Terhadap Kualitas Hasil Kerja Auditor. Simposium Nasional Akuntansi X, Unhas Makassar 26 - 28 Juli 2007.

Pabundu, T. (2005). Budaya Organisasi dan Peningkataan Kinerja Perusahaan. Jakarta: PT Bumi Aksara.

Prasetyono dan Kompyurini, N. (2007). "Analisis Kinerja Rumah Sakit Swasta Berdasarkan Budaya Organisasi, Komitmen Organisasi dan Akuntabilitas Publik", Jurnal Akuntansi Sektor Publik, Pontianak: Simposium Nasional Akuntansi XI,

Robbins, S. P. (2003). Perilaku Organisasi, Jilid 2. Jakarta: PT. Indeks Kelompok Gramedia.

Sopiah. (2008). Perilaku Organisasional, Yogyakarta: CV Andi Offset.

Sugiyono. (2009). Metode Penelitian Bisnis (Pendekatan Kuantitatif, Kualitatif, dan R\&D), Bandung: CV. Alfabeta.

Sugiyono. (2007). Statistik Untuk Penelitian. Bandung: CV Alphabet.

Supeno, A. (2012). Awas orang miskin tidak boleh sakit. Kompasiana 19 April 2012. Diakses pada 19 April 2012, dari http://kesehatan.kompasiana.com/medis/2012/04/08/awas-hati-hati-orangmiskin-tidak-boleh-sakit-453402.html

Trisnaningsih, S. (2007). Independensi Auditor dan Komitmen Organisasi sebagai Mediasi Pengaruh Pemahaman Good Governance, Gaya Kepemimpinan dan Budaya Organisasi Terhadap Kinerja Auditor. Jurnal Akuntansi Manajemen Keperilakuan. Jawa Timur: Simposium Nasional Akuntansi X,

Tjiptono, F. (2000). Prinsip \& Dinamika Pemasaran. Edisi Pertama. Yogyakarta: J \& J Learning.

Wijayanti, D. (2008). Pengaruh Komitmen Terhadap Kepuasan Kerja Auditor Internal: Motivasi Sebagai Variabel Moderating. Jurnal Simposium Nasional Akuntansi 11, Pontianak. 